\title{
Use of desflurane in neurosurgery: Cons
}

\author{
Shashi Srivastava
}

\begin{abstract}
Desflurane is being projected nowadays as inhalational agent of choice in the repertoire of the modern day anaesthesiologists. Refinement of its pharmacologic properties from its predecessors has attracted the attention of clinicians towards this novel agent. However, within the realms of neurosurgical anaesthesiology, the widespread use of desflurane today should be, at best viewed with a bit of caution. Although a sizeable number of advantages of using desflurane exist, anaesthesiologists dealing with neurosurgical patients should be cognizant of its drawbacks.
\end{abstract}

Key words: Intracranial pressure, desflurane, emergence

\section{INTRODUCTION}

Desflurane with its favourable pharmacokinetic and pharmacodynamic profile though is an attractive inhalational agent, suitable for all age groups and surgeries but its use in neuroanaesthesia is not devoid of adverse effects such as increase in the intracranial pressure (ICP) due to various reasons and dose-related sympathetic stimulation confers the advantage of precise control of anaesthetic depth along with rapid, predictable and clear-headed recovery making it a popular component of neurosurgical anaesthesiology. In spite of its obvious advantages, desflurane has its share of adverse effects which limits its universal usage.

Desflurane being extremely volatile (boiling point $23.5^{\circ} \mathrm{C}$ ) requires specialised vaporizer to ensure its appropriate delivery which requires external power supply. Thus, conventional vaporizers cannot be used for its delivery. Due to its pungent strong odour, it cannot be used for inhalational induction.

Department of Anaesthesiology, SGPGIMS, Lucknow, Uttar Pradesh, India

Address for correspondence:

Dr. Shashi Srivastava, Department of Anaesthesiology, SGPGIMS,

Lucknow - 226 014, Uttar Pradesh, India.

E-mail: shashian2014@gmail.com

\begin{tabular}{|l|l|}
\hline \multicolumn{2}{|c|}{ Access this article online } \\
\hline Quick Response Code: & Website: \\
\hline & www.jnaccjournal.org \\
\cline { 2 - 2 } & \\
\hline & \\
\hline
\end{tabular}

In the presence of dry soda lime and high temperatures, desflurane can degrade and produce carbon monoxide. ${ }^{[1]}$ The rare possibility of development of malignant hyperthermia as with other inhalational agent exists with the use of desflurane, however, the onset may be delayed. ${ }^{[2]}$

On clinical usage, desflurane affects cardiovascular system directly or by activation of sympathetic nervous system. ${ }^{[3-5]}$ The dose dependent decrease in arterial blood pressure and systemic vascular resistance can be detrimental in patients with pre-existing cardiovascular diseases. On the other hand, the central stimulation of sympathetic nervous system causes release of catecholamines and sympathetic surges ${ }^{[6]}$ Desflurane has a ceiling effect and higher doses augment sympathetic tone. ${ }^{[7]}$ The rapidity of concentration change of desflurane influences the degree of sympathetic stimulation and thus it is advisable to change the desflurane concentration slowly $(0.5 \%-1 \%$ increments every $2-3$ breaths) to attenuate these response in 'at risk' patients. Bilotta et al. in their study in obese patients undergoing craniotomy though found earlier post-operative cognitive recovery in desflurane group in comparison to sevoflurane, had another clinically relevant finding that despite similar haemodynamics, use of vasoactive drugs (to keep MAP within $20 \%$ of baseline) was more frequent in desflurane group. ${ }^{[8]}$ In a recent study by

This is an open access article distributed under the terms of the Creative Commons Attribution-NonCommercial-ShareAlike 3.0 License, which allows others to remix, tweak, and build upon the work non-commercially, as long as the author is credited and the new creations are licensed under the identical terms.

For reprints contact: reprints@medknow.com

How to cite this article: Srivastava S. Use of desflurane in neurosurgery: Cons. J Neuroanaesthesiol Crit Care 2017;4:S85-7. 
Dube et al., in supratentorial craniotomy no difference in post-operative cognitive function was found between desflurane and sevoflurane. ${ }^{[9]}$ This finding is supported by some more recent studies.

Its adverse clinical effects on the pulmonary system include respiratory depression, airway irritation and bronchospasm. Respiratory irritation can occur at 1-1.5 minimum alveolar concentrations (MACs). ${ }^{[10]}$ Factors influencing airway irritation includes age (more in younger age group), opioid administration (reduces incidence) and smoking. Desflurane is not approved for induction and maintenance in paediatric patients for its irritative properties. Laryngeal mask airway removal following desflurane anaesthesia in children below 6 years warrant caution because of a high incidence of undesirable responses (coughing, laryngospasm). ${ }^{[11]}$ In adult patients with chronic obstructive pulmonary disease, desflurane might precipitate bronchospasm and hypersecretion. Its potential to increase airway resistance at higher MAC values questions its usage in this subset of patients. Central depression of respiratory drive is greater with desflurane in comparison to isoflurane. ${ }^{[12]}$

Neurologically, desflurane administration causes dose-dependent vasodilation and increases the cerebral blood flow (CBF). At >1.5 MAC, vasodilatation caused by desflurane is higher compared to halothane. ${ }^{[13,14]}$ Desflurane, when used in children for rapid emergence from propofol anaesthesia was associated with increase in middle cerebral artery blood flow velocity which may be clinically significant in patients with intracranial pathology ${ }^{[15]}$ In animal studies also desflurane was found to cause more cerebral vasodilation and higher ICP than isoflurane at normocapnia which was not significant with hypocapnia. ${ }^{[16]}$ In eight non-neurosurgical procedures, desflurane at a concentration of 1 MAC or above found to cause significant impairment in cerebral autoregulation. ${ }^{[17]}$ Compared to isoflurane cerebrospinal fluid production is more with desflurane, raising concerns of ICP rise. ${ }^{[18]}$

Desflurane has been shown to cause relaxation of the neuromuscular junction and potentiates the action of neuromuscular blocking drugs to a greater degree as compared to isoflurane. The prolongation of response times with desflurane can assume clinical significance and is undesirable in patients with pre-existing neuromuscular weakness like GuillianBarre syndrome.

Last but not the least, without the use of low flow techniques, closed circuits and efficient scavenging techniques, the overall cost of anaesthesia tends to be higher and is associated with implications of environmental pollution.
The benefits of early recovery from anaesthesia in neurosurgical patients administered desflurane should be considered with risks such as haemodynamic instability and increase in ICP.

\section{CONCLUSION}

Desflurane, in spite of the plethora of advantages surrounding its use, is not devoid of its share of adverse effects. Its cardiovascular effects (higher sympathetic surges), intracranial effects (higher CBF and CSF production at higher MAC's), potential to cause malignant hyperthermia, higher costs and propensity to cause environmental pollution limits the advocacy of its universal applicability. Neuroanaesthesiologists thus should be aware of these limitations of desflurane and individualise its application on case to case basis.

\section{Financial support and sponsorship} Nil.

\section{Conflicts of interest}

There are no conflicts of interest.

\section{REFERENCES}

1. Kapoor MC, Vakamudi M. Desflurane - Revisited. J Anaesthesiol Clin Pharmacol 2012;28:92-100.

2. Wedel DJ, Gammel SA, Milde JH, Iaizzo PA. Delayed onset of malignant hyperthermia induced by isoflurane and desflurane compared with halothane in susceptible swine. Anesthesiology 1993;78:1138-44.

3. Muzi M, Lopatka CW, Ebert TJ. Desflurane-mediated neurocirculatory activation in humans. Effects of concentration and rate of change on responses. Anesthesiology 1996;84:1035-42.

4. Muzi M, Ebert TJ, Hope WG, Robinson BJ, Bell LB. Site(s) mediating sympathetic activation with desflurane. Anesthesiology 1996;85:737-47.

5. Muzi M, Ebert TJ. A comparison of baroreflex sensitivity during isoflurane and desflurane anesthesia in humans. Anesthesiology 1995;82:919-25.

6. Weiskopf RB, Eger EI $2^{\text {nd }}$, Daniel $M$, Noorani $M$. Cardiovascular stimulation induced by rapid increases in desflurane concentration in humans results from activation of tracheopulmonary and systemic receptors. Anesthesiology 1995;83:1173-8.

7. Kaye AD, Kucera IJ, Heavner J, Gelb A, Anwar M, Duban M, et al. The comparative effects of desflurane and isoflurane on lumbar cerebrospinal fluid pressure in patients undergoing craniotomy for supratentorial tumors. Anesth Analg 2004;98:1127-32.

8. Bilotta F, Doronzio A, Cuzzone V, Caramia R, Rosa G; PINOCCHIO Study Group. Early postoperative cognitive recovery and gas exchange patterns after balanced anesthesia with sevoflurane or desflurane in overweight and obese patients undergoing craniotomy: A prospective randomized trial. J Neurosurg Anesthesiol 2009;21:207-13.

9. Dube SK, Pandia MP, Chaturvedi A, Bithal P, Dash HH. Comparison of intraoperative brain condition, hemodynamics and postoperative recovery between desflurane and sevoflurane in patients undergoing supratentorial craniotomy. Saudi J Anaesth 2015;9:167-73. 
10. Arain SR, Shankar H, Ebert TJ. Desflurane enhances reactivity during the use of the laryngeal mask airway. Anesthesiology 2005; 103:495-9.

11. Isik Y, Goksu S, Kocoglu H, Oner U. Low flow desflurane and sevoflurane anaesthesia in children. Eur J Anaesthesiol 2006;23:60-4.

12. Lockhart SH, Rampil IJ, Yasuda N, Eger EI $2^{\text {nd }}$, Weiskopf RB. Depression of ventilation by desflurane in humans. Anesthesiology 1991;74:484-8.

13. Matta BF, Mayberg TS, Lam AM. Direct cerebrovasodilatory effects of halothane, isoflurane, and desflurane during propofol-induced isoelectric electroencephalogram in humans. Anesthesiology 1995;83:980-5.

14. Ornstein E, Young WL, Fleischer LH, Ostapkovich N. Desflurane and isoflurane have similar effects on cerebral blood flow in patients with intracranial mass lesions. Anesthesiology 1993;79:498-502.

15. Barlow R, Karsli C, Luginbuehl I, Bissonnette B. Desflurane increases cerebral blood flow velocity when used for rapid emergence from propofol anesthesia in children. Can J Anaesth 2004;51:824-8.

16. Holmström A, Akeson J. Desflurane increases intracranial pressure more and sevoflurane less than isoflurane in pigs subjected to intracranial hypertension. J Neurosurg Anesthesiol 2004;16:136-43.

17. Bedforth NM, Girling KJ, Skinner HJ, Mahajan RP. Effects of desflurane on cerebral autoregulation. Br J Anaesth 2001;87:193-7.

18. Artru AA, Powers K, Doepfner P. CSF, sagittal sinus, and jugular venous pressures during desflurane or isoflurane anesthesia in dogs. J Neurosurg Anesthesiol 1994;6:239-48. 